\title{
Examining university students' behavioural intention to use e-learning during the COVID-19 pandemic: An extended TAM model
}

\author{
Mailizar Mailizar $^{1}$ D $\cdot$ Damon Burg $^{2}$ D . Suci Maulina ${ }^{3}$
}

Received: 24 January 2021 / Accepted: 19 April 2021 / Published online: 28 April 2021

(c) The Author(s), under exclusive licence to Springer Science+Business Media, LLC, part of Springer Nature 2021

\begin{abstract}
This present study aims to investigate factors that impact behavioural intention of university students on e-learning use during the COVID-19 pandemic. An online questionnaire was utilised to gather data from 109 students enrolled in one of the universities in Indonesia. The Technology Acceptance Model (TAM) was the primary framework employed for analysis, in which system quality and e-learning experience were included as external constructs to seek out a much better model to improve the understanding of students' intention to adopt e-learning. An extended TAM model was developed and tested in this study. The model consists of six constructs: system quality, e-learning experience, perceived ease of use, perceived usefulness, attitude toward use, and behavioural intention. Structural Equation Modelling (SEM) and SMART PLS 3.0 software were applied for data analysis. The findings informed that the proposed model has been successfully explained factors university students use of e-learning during the pandemic in Indonesia. It suggested that attitude toward e-learning use was the most prominent construct to predict university students' behavioural intention to use e-learning during the pandemic. Finally, this study offers recommendations for future research and practices.
\end{abstract}

Keywords E-learning · Extended TAM · University students · COVID-19 . Indonesia

\section{Introduction}

The coronavirus diseases 2019 (COVID-19) that emerged in late December has spread around the globe. In response to this, many countries have imposed restrictions, including university closure. The literature shows that the closure of

Mailizar Mailizar

mailizar@unsyiah.ac.id

Extended author information available on the last page of the article 
educational institutions would reduce the spread of infection disease (Kawano \& Kakehashi, 2015; Wheeler et al., 2010). Growing numbers of universities around the globe have rapidly transitioned course from offline to online learning, including Indonesia which has switched conventional classes to remote learning. Therefore, this leaves about 4000 higher education institutions in the country dependent on online teaching and learning.

A Learning Management System (LMS) such as Moodle, Blackboard and Brightspace are well-known technologies developed to support the implementation of distance teaching and learning processes (Dahlstrom et al., 2014; McGill et al., 2011). By offering multiple learning tools, a LMS provides a virtual way of communicating and accommodates speed and allows effectiveness in instructional processes (Fathema et al., 2015). In the context of this study, we investigated Learning Management System (Moodle), which is an e-learning platform being used at the university where the study was conducted.

Technology Acceptance Model (TAM) (Davis, 1986) is a widely used model in studies of users' technology acceptance (Cigdem \& Topcu, 2015). The main purpose of the model is to elucidate users' behaviours toward technology adoption (Chang et al., 2017). Furthermore, previous studies have extended the TAM model, which has resulted in numerous external factors (Abdullah \& Ward, 2016; Martin, 2012; Williams \& Williams, 2010). Abdullah and Ward (2016) conducted a meta-analysis study and found that subjective norm, experience, perceived enjoyment, computer anxiety, and self-efficacy are mostly used external factors for the TAM model. They also pointed out that experience is the fifth most frequently used external factor in the e-learning context.

The previous studies using experience as an external factor of TAM model looked at different types of users of e-learning, namely, employees (Lee et al., 2011, 2013; Purnomo \& Lee, 2013), students (Lau \& Woods, 2008; Rezaei et al., 2008; Williams \& Williams, 2010), students and educators (Martin, 2012), and teachers (De Smet et al., 2012). Furthermore, prior studies used various kinds of experiences, such as internet experience (Premchaiswadi et al., 2012), technology experience (Al-alak \& Alnawas, 2011; Teo et al., 2017), computer efficacy as user's prior experience (Waheed \& Jam, 2010), and online learning experience (Liu et al., 2010). However, a few studies used e-learning experience in high school as an external factor to examine university students' behavioural intention toward e-learning utilisation. Moreover, a significant number of previous studies examined the impact of system quality on students and instructors' behavioural intention in adopting e-learning. The prior studies revealed that system quality has significantly impacted perceived usefulness (Fathema \& Sutton, 2013; Fathema et al., 2015; Park et al., 2012), attitude toward using (Fathema \& Sutton, 2013), and behavioural intention to use (Fathema \& Sutton, 2013; Park et al., 2012).

In the context of the COVID19 pandemic, several studies have addressed e-learning adoption issues during the pandemic in the context of higher education (Almaiah et al., 2020; Ho et al., 2020; Siron et al., 2020; Sukendro et al., 2020; Vladova et al., 2021). In terms of Indonesian higher education, Siron et al. (2020) and (Sukendro et al., 2020) have conducted studies to explore factors predicting the use of e-learning during the pandemic. Both studies used the TAM model (Davis, 1986) as the theoretical framework. Sukendro et al. (2020) extended TAM model by 
adding facilitating condition as an external factor, while Siron et al. (2020) included experience, perceived enjoyment, and computer anxiety as external variables of the TAM model. However, their study did not particularly address the experience of e-learning use.

However, there is a dearth of study about university students' behavioural intention to use e-learning during the pandemic that adopts the TAM model with e-learning experience and system quality as external factors of the model, particularly in the context of developing counties, including Indonesia, where e-learning is not well adopted at universities before the pandemic. Therefore, this study aimed to examine factors predicting Indonesian university students' behavioral intention to use e-learning during the pandemic. The study adopted the TAM model as a theoretical foundation and employed Structural Equation Modelling (SEM) to assess the relationship between exogenous and endogenous constructs. It is necessary to conduct this study to understand factors affecting university students' intention to continue using e-learning during the pandemic and even beyond since the pandemic is still dangerous, and university closures are still extended in Indonesia. This study contributes to the literature regarding e-learning adoption during the pandemic in the context of higher education in a developing country. In addition, this study offers implications for universities and policymakers to better prepare for e-learning adoption during the pandemic and beyond.

\section{Theoretical framework}

According to Davis (1986), how and when users will adopt and use new technology could be investigated by Technology Acceptance Model (TAM) (Fig. 1). This model is the most widely used framework to investigate users' attitude and intention to adopt technology.

Teo (2010) argues that TAM is efficient in explaining users' behaviour to use computing technology. According to Davis (1989), behavioural intention is influenced by attitude toward use, and it is directly and indirectly affected by perceived ease of use and perceived usefulness. Attitude is an important factor in explaining users' technology usage behaviour (Cruz-Cárdenas et al., 2019). In addition,

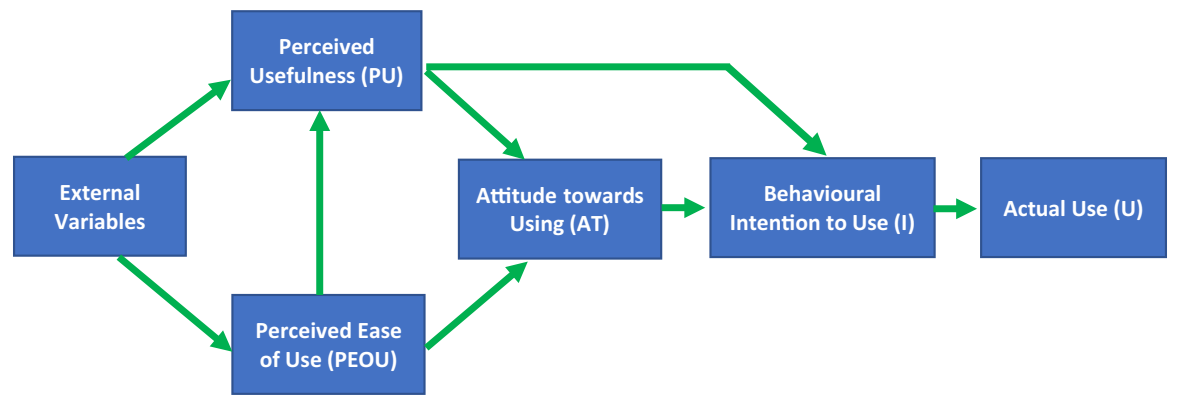

Fig. 1 Technology Acceptance Model (Davis, 1986) 
intention to use is a more progressive dependent variable compared to actual use (Teo, 2010). Thus, in this current study, we used behavioural intention to use e-learning as a dependent variable.

\subsection{System Quality (SQ) as an external variable of TAM}

System Quality (SQ), in this current study, refers to the quality associated to function, speed, features, and contents of LMS being used at the university. Previous studies showed that SQ had a significant influence on Perceived Usefulness (PU) of e-learning system (Fathema \& Sutton, 2013; Park et al., 2012). Furthermore, prior studies also reported that SQ significantly affected users' attitude (Fathema \& Sutton, 2013; Fathema et al., 2015), and behavioural intention to adopt the technology (Fathema et al., 2015; Park et al., 2012). Based on the existing literature, we proposed three hypotheses as to how SQ relates to PU, AT, and BI.

H1:System Quality (SQ) significantly and positively affects Perceived Usefulness (PU) of e-learning.

H2:System Quality (SQ) significantly and positively affects Attitude toward Using (AT) e-learning.

H3:System Quality (SQ) significantly and positively affects Behavioural Intention $(\mathrm{BI})$ to use e-learning.

\subsection{Experience (XS) as an External Variable of TAM}

Experience is defined as "an individual's involvement or action in something over a period of time" (Abbasi et al., 2011, p.37). In this study, we refer to experience to the extent to which students involve or engage in a particular task using e-learning during their study in high schools. There is a body of literature, as mentioned earlier, examining the effect of experience on perceived ease of use (PEU) and perceived usefulness (PU). The prior studies found that experience positively impacted users' perceived ease of use toward e-learning usage (Abdullah \& Ward, 2016; Armenteros et al., 2013; Chang et al., 2017; De Smet et al., 2012; Lee et al., 2011; Tarhini et al., 2015). Furthermore, it has been proven that past experience highly influenced users' perceived usefulness in using e-learning (Abdullah et al., 2016; Chang et al., 2017; Lee et al., 2013; Liu et al., 2010; Martin, 2012). Therefore, two hypotheses were offered to evaluate the effect of prior e-learning experience of university students on their PEU and PU.

H4:Previous e-learning experience (XS) significantly and positively affects Perceived Ease of Use (PEU) of e-learning.

H5:Previous e-learning experience (XS) significantly and positively affects Perceived Usefulness (PU) of e-learning. 


\subsection{Perceived Ease of Use (PEU)}

In the e-learning context, Lin et al. (2010) defined Perceived Ease of Use (PEU) as the extent to which users believe that employing an e-learning system will be effortless. Previous research has confirmed that perceived ease of use significantly affected perceived usefulness (Abdullah et al., 2016; Binyamin et al., 2019; Joo et al., 2018; Zogheib et al., 2015). Furthermore, prior studies showed that perceived ease of use strongly predicted attitude toward the use of e-learning (Fokides, 2017; Teo, 2012; Wong, 2015; Zogheib et al., 2015). Based on previous studies, the following hypotheses were examined.

H6:Perceived Ease of Use (PEU) significantly and positively affects Perceived Usefulness (PU) of e-learning.

H7:Perceived Ease of Use (PEU) significantly and positively affects Attitude toward Using (AT) of e-learning.

\subsection{Perceived Usefulness (PU)}

According to Lin, Chen, and Fang (2010), in the e-learning context, perceived usefulness (PU) is described as the degree to which users believe that e-learning can support them to achieve teaching and learning objectives. Previous studies showed that PU had the most significant influence on attitude (Martinho et al., 2018; Ritter, 2017; Tarhini et al., 2015; Teo, 2012; Wong, 2015; Zogheib et al., 2015). Furthermore, PU also had a significant impact on behavioural intention toward e-learning adoption (Abdullah et al., 2016; Martinho et al., 2018; Scherer et al., 2019; Wong, 2015). Based on the prior studies, we proposed the following hypotheses.

H8:Perceived Usefulness (PU) significantly and positively affects Attitude (AT) toward using e-learning.

H9:Perceived Usefulness (PU) significantly and positively affects Behavioural Intention (BI) to use e-learning.

\subsection{Attitude toward using (AT)}

According to Kaplan (1972), attitude as a tendency in response to an event in a favourable or an unfavourable way. Previous studies on e-learning acceptance have indicated attitude as a determinant factor of behavioural intention toward e-learning usage (e.g., Cheung \& Vogel, 2013; Tosuntaş et al., 2015). Attitude is found to be a dominant factor to influence behavioural intention (Chu \& Chen, 2016; Hussein, 2017; Teo, 2012; Teo et al., 2017; Zogheib et al., 2015). Drawing upon the findings of those studies, we formulated the following hypothesis.

H10:Attitude (AT) significantly and positively affects Behavioural Intention (BI) to use e-learning. 


\subsection{Behavioural Intention (BI)}

Behavioural Intention (BI) is "a cognitive process of individuals' readiness to perform specific behaviour and is an immediate antecedent of usage behaviour" (Abbasi et al., 2011). BI is the key factor that determines the success of a system (Abdullah \& Ward, 2016; Armenteros et al., 2013; Chang et al., 2017; De Smet et al., 2012; Lee et al., 2011; Tarhini et al., 2015). In the initial TAM model (Davis, 1989), attitude, perceived usefulness and perceived ease of use have an impact on BI.

\subsection{Research model}

The discussion presented previously suggests that prior e-learning experience and system quality are critical determinants of attitude and behavioural intention of e-learning usage. As mentioned earlier, in the current study, students' experiences in e-learning during their high school and system quality were added as external factors of the TAM model, as shown in Fig. 2.

\section{Method}

\subsection{Design of the study}

In this current research, we employed a quantitative approach with a cross-sectional survey (Fraenkel, 2011). We used this method as it is considered being able to provide reliable, valid, and generalisable findings (Fraenkel et al., 2011). Furthermore, a questioner survey can be administered to a large number of respondents. In addition, a quantitative study enables researchers to make a generalisation about a population when the data are collected from a representative sample (Fraenkel et al., 2011).

\subsection{Instrument design and development}

In this study, we adapted research instruments to measure factors predicting the university students' adoption of e-learning during the pandemic. Regarding system quality,

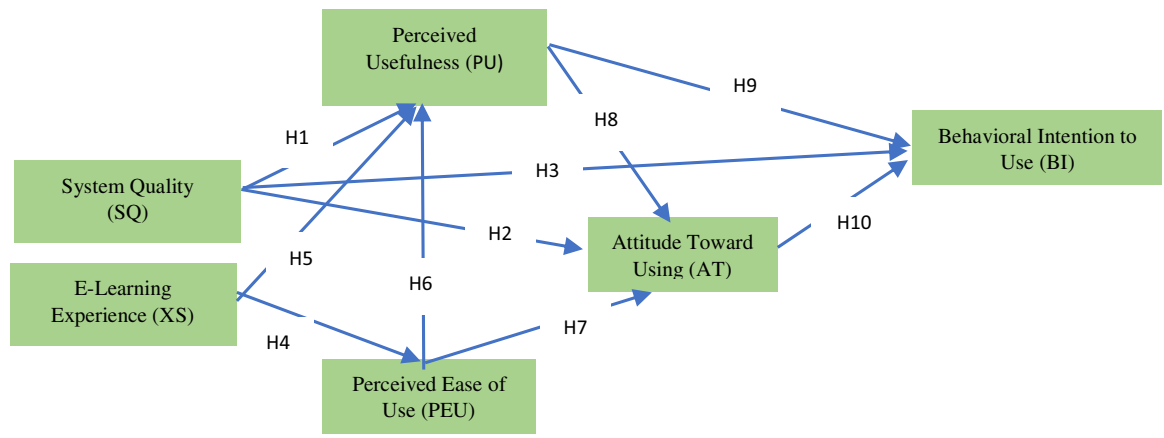

Fig. 2 The structural model of the hypotheses 
items were adopted from (Pham et al., 2019). Furthermore, for the other constructs, we adopted from (Al-Adwan et al., 2013; Davis, 1989; Venkatesh \& Bala, 2008). Regarding the adaptation process, for the present study, the instrument was established in which indicators were differed and developed to suit the context of using e-learning during the pandemic. In the first phase, 32 indicators were established for the instruments based on TAM construct TAM constructs (PEU, PU, AT and BI) with two external variables, namely e-learning experience (XS) and system quality (SQ). The instrument was then discussed with three experts as part of content validity to ensure the instrument is appropriate the context of the study (Lynn, 1986). After validation, four indicators were dropped, the remaining 28-questions were distributed for a pilot test. Aiming to examine initial reliability before the data collection, we evaluated Cronbach's alpha, and the result showed that there was no construct that has an alpha value below the threshold of 0.7 as suggested by Hair et al. (2016). The final version of the research instrument is attached in the Appendix Table 8.

\subsection{Participants of the study}

The population of this study were about 15.000 students enrolled at one of the public universities in Indonesia. They enrolled at a four-year undergraduate program in various program of studies. In total, there were 109 students who responded to the questionnaires. According to Hair et al. (2016), a quantitative study requires an adequate sample size. Various rules have been suggested to determine an adequate sample size for regression analysis. Hair et al. (2016) suggests that the most widely used sample size estimation method in PLS-SEM is the '10-time rules', indicating that sample size should be equal to the larger values between the construct with the biggest number of formative indicator and the endogenous construct with the largest number of independent exogeneous construct predicting it. The endogenous construct. Considering the sample size consideration, 109 responses of the survey are a sufficient number of sample size. Further details of the participants' background information are presented in Table 1.

\subsection{Data collection}

Prior data collection, we acquired ethical approval for this study. Futhermore, we used a questioner survey as it is one of a widely used methods in technology acceptance research (Lew et al., 2019). Furthermore, we conducted an online survey due to its easiness and accessibility to multiple devices (See., Fraenkel et al., 2011). As the participants were studying from home, we approached the participants through a message feature in the e-learning system and WhatsApp group. A link to a questionnaire hosted on Google form was sent to participants and the questionnaire was open for two weeks.

\subsection{Data analysis}

We utilised structural equation modelling (SEM) to examine the proposed hypotheses. Partial least squares SEM (PLS-SEM) is a suitable choice regarding the aim of 
Table 1 Participants' demographic background

\begin{tabular}{llll}
\hline Demographic Background & & $\begin{array}{l}\text { Number of Partici- } \\
\text { pants }\end{array}$ & Percentage \\
\hline Gender & Male & 12 & $11.01 \%$ \\
& Female & 97 & $88.99 \%$ \\
Device being used for & Mobile/handheld device & 48 & $44.04 \%$ \\
e-learning & Computer/laptop & 61 & $55.96 \%$ \\
Internet connection & Landline connection & 25 & $22.94 \%$ \\
& Mobile phone & 83 & $76.15 \%$ \\
& Modem & 1 & $0.91 \%$ \\
\hline
\end{tabular}

this study. As such, we employed SMART PLS 3.0 to measure confirmatory factor analysis (CFA) and to confirm the reliability, validity, and internal consistency of the model.

\section{Results}

In this section, we report the results of factor analysis and hypothesis testing.

\subsection{Factor analysis}

To assess factor analysis, we first identified six constructs included in our model namely, PEU, PU, AT, BI, XS, and SQ. The structural model and its path coefficients are depicted in Fig. 3.

To examine the predictive accuracy of the model, we determined $\mathrm{R}^{2}$ values. From Fig. 3, it shows that $\mathrm{R}^{2}$ is 0.571 for BI. This indicates that the three exogenous constructs (SQ, PU and AT) explain $57.1 \%$ of the variance in BI (Hair et al., $2017)$. The inner model shows that AT is the only strong predictor of BI $(\beta=0.513$, $\mathrm{t}$-value =5.299), on the other hand, SQ $(\beta=0.081$, t-value =1.062) and PU $(\beta=0.119$, $t$-value $=1.033)$ are not. Having $\mathrm{t}$-value $<1.645$ for a significant level of $5 \%(\alpha=0.05)$ in the one-tailed test indicates that SQ and PU did not possess a strong positive relationship with BI (Hair et al., 2017).

Referring to AT as an endogenous construct, the model indicates that $\mathrm{R}^{2}$ is 0.666 for AT. This implies that the three constructs (SQ, PEU and PU) explain $66.16 \%$ of the variance in AT. This model also indicates that PU is the strongest predictor of AT $(\beta=0.535$, t-value $=6.951)$, followed by SQ $(\beta=0.270$, t-value $=3.447)$ and PEU $(\beta=0.141$, $t$-value $=2.138)$, Having t-values $>1.645$ for significant level of $5 \%$ $(\alpha=0.05)$ in the one-tailed test concludes that PU, SQ and PEU had a significant relationship with AT (Hair et al., 2017).

Furthermore, for PU as an endogenous construct, Fig. 3 shows that $\mathrm{R}^{2}$ is 0.443 , indicating that the two constructs (PEU and XIT) explain $44.3 \%$ of the variance in PU. The model reveals that SQ is the strongest predictor of PU $(\beta=0.417$, $\mathrm{t}$-value $=4.822)$ and PEU follows $(\beta=0.317$, $\mathrm{t}$-value $=4.056)$. This confirms that both SQ and PEU had a strong positive relationship with PU. 


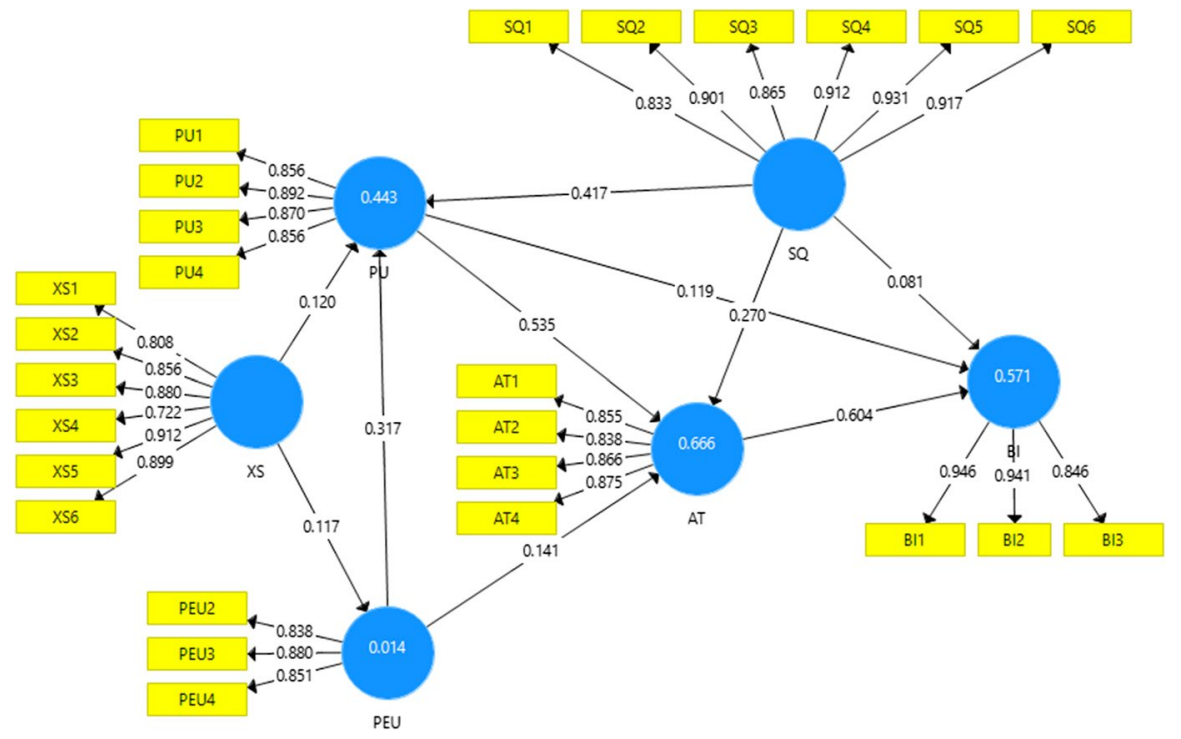

Fig. 3 Structural model and path coefficients

Additionally, we employed three assessment criteria, namely convergent validity, internal consistency reliability, and discriminant validity to assess the theoretical model. First, regarding convergent validity, we examined the outer loadings of the indicators and the averaged variance extracted (AVE) (Hair et al., 2017). An adequate convergent validity is indicated by loading values equal or larger than 0.7 (Hair et al., 2017). Second, composite reliability (CR) was measured to confirm internal consistency reliability. CR values above 0.7 means adequate consistency reliability. Third, we employed the cross-loading criterion (Hair et al., 2017) and the Heterotrait-Monotrait ratio of correlation (HTMT) (Henseler et al., 2015) to assess discriminant validity. Constructs meet established discriminant validity when the square roots of AVEs for all constructs are higher than the value of inter-construct on the same columns and row.

Table 2 presents loading values, CR and AVE of the constructs. Except for the indicator of PEU1, which was removed, all indicators had loadings over 0.7, indicating acceptable and high convergent validity (Hair et al., 2017). It implies that the indicator reliability was satisfied. In addition, values of AVE reached the satisfactory level of AVE $(\geq 0.5)$, which indicates that convergent validity was evident (Hair et al., 2017). As a result, it confirms that the constructs satisfied the requirement of reliability and convergent validity.

Table 3 demonstrates that every construct had adequate discriminant validity for AT (0.859), BI (0.913), PEU (0.856), PU (0.869), SQ (0.894), and XS (0.849). Furthermore, Table 4 shows that the loading values of all indicators on the computed constructs were all higher than the loading values on the other constructs. This indicates that the indicators of the other constructs were interchangeable. 
Table 2 Convergent validity and composite reliability

\begin{tabular}{|c|c|c|c|c|}
\hline Construct & Items & Loadings & CR & AVE \\
\hline \multirow[t]{4}{*}{ Perceived Usefulness (PU) } & PU1 & 0.856 & \multirow[t]{4}{*}{0.925} & \multirow[t]{4}{*}{0.755} \\
\hline & PU2 & 0.892 & & \\
\hline & PU3 & 0.870 & & \\
\hline & PU4 & 0.856 & & \\
\hline \multirow[t]{3}{*}{ Perceived Ease of Use (PEU) } & PEU2 & 0.838 & \multirow[t]{3}{*}{0.892} & \multirow[t]{3}{*}{0.733} \\
\hline & PEU3 & 0.880 & & \\
\hline & PEU4 & 0.851 & & \\
\hline \multirow[t]{4}{*}{ Attitude toward Using (AT) } & AT1 & 0.855 & \multirow[t]{4}{*}{0.918} & \multirow[t]{4}{*}{0.738} \\
\hline & AT2 & 0.838 & & \\
\hline & AT3 & 0.866 & & \\
\hline & AT4 & 0.875 & & \\
\hline \multirow[t]{3}{*}{ Intention to Use (BI) } & BI1 & 0.946 & \multirow[t]{3}{*}{0.937} & \multirow[t]{3}{*}{0.833} \\
\hline & $\mathrm{BI} 2$ & 0.941 & & \\
\hline & $\mathrm{BI} 3$ & 0.846 & & \\
\hline \multirow[t]{6}{*}{ E-learning experience (XS) } & XS1 & 0.808 & \multirow[t]{6}{*}{0.939} & \multirow[t]{6}{*}{0.720} \\
\hline & $\mathrm{XS} 2$ & 0.856 & & \\
\hline & XS3 & 0.880 & & \\
\hline & XS4 & 0.722 & & \\
\hline & XS5 & 0.912 & & \\
\hline & XS6 & 0.899 & & \\
\hline \multirow[t]{6}{*}{ System Quality } & SQ1 & 0.833 & \multirow[t]{6}{*}{0.960} & \multirow[t]{6}{*}{0.799} \\
\hline & SQ2 & 0.901 & & \\
\hline & SQ3 & 0.865 & & \\
\hline & SQ4 & 0.912 & & \\
\hline & SQ5 & 0.931 & & \\
\hline & SQ6 & 0.917 & & \\
\hline
\end{tabular}

PEU1 was deleted due to low loading

As suggested by Henseler (2010), we also made use of Heterotrait-Monotrait ratio of correlation (HTMT), which is another method to examine discriminant validity. This method is to confirm that the constructs included in this study differ from one to another. Table 5 shows that there was no confidence interval of HTMT value that contains the value of 1 , indicating that the constructs had sufficient discriminate validity (See., Henseler, 2010). As a result, it is confirmed that the constructs had sufficient discriminant validity.

\subsection{Hypothesis testing}

The results of the structural model are shown in Table 6. First, we addressed the lateral collinearity issue by measuring the variance inflation factor (VIF). VIF values need to be above 0.2 and below 5.0 (Hair et al., 2017). Table 6 indicates that all of the inner VIF values were above 0.2 and below 5.0. Hence, it is confirmed that there was no concern about lateral multicollinearity of this study. 
Table 3 Discriminant validity (Fornell-Lacker Criterion)

\begin{tabular}{lllllll}
\hline & AT & BI & PEU & PU & SQ & XS \\
\hline AT & 0.859 & & & & & \\
BI & 0.748 & 0.913 & & & & \\
PEU & 0.552 & 0.503 & 0.856 & & & \\
PU & 0.769 & 0.631 & 0.529 & 0.869 & & \\
SQ & 0.653 & 0.545 & 0.473 & 0.590 & 0.894 & \\
XS & 0.224 & 0.162 & 0.117 & 0.237 & 0.190 & 0.849 \\
\hline
\end{tabular}

Second, using the bootstrapping function of SMART PLS 3, we generated t-values for all paths to test the significant level. Moreover, to evaluate the effect size of SQ, PU, and AT on BI, in addition to the effect size of SQ, PEU and PU on AT, we used Cohen's f ${ }^{2}$ (Cohen, 2013).

Overall, Table 6 reveals that six out of ten relationships had t-value $>1.645$. Therefore, they were significant at 0.05 level of significance. Experience using

Table 4 Discriminant validity (cross loading criterion)

\begin{tabular}{lllllll}
\hline & AT & BI & PEU & PU & SQ & XS \\
\hline AT1 & 0.855 & 0.640 & 0.456 & 0.663 & 0.515 & 0.090 \\
AT2 & 0.838 & 0.616 & 0.523 & 0.650 & 0.585 & 0.228 \\
AT3 & 0.866 & 0.652 & 0.474 & 0.670 & 0.614 & 0.259 \\
AT4 & 0.875 & 0.661 & 0.444 & 0.658 & 0.527 & 0.191 \\
BI1 & 0.725 & 0.946 & 0.458 & 0.631 & 0.513 & 0.157 \\
BI2 & 0.712 & 0.941 & 0.496 & 0.613 & 0.553 & 0.196 \\
BI3 & 0.603 & 0.846 & 0.422 & 0.470 & 0.418 & 0.080 \\
PEU2 & 0.439 & 0.390 & 0.838 & 0.442 & 0.307 & 0.011 \\
PEU3 & 0.479 & 0.464 & 0.880 & 0.444 & 0.433 & 0.089 \\
PEU4 & 0.497 & 0.437 & 0.851 & 0.470 & 0.466 & 0.189 \\
PU1 & 0.620 & 0.495 & 0.398 & 0.856 & 0.455 & 0.229 \\
PU2 & 0.671 & 0.593 & 0.435 & 0.892 & 0.422 & 0.216 \\
PU3 & 0.681 & 0.570 & 0.428 & 0.870 & 0.585 & 0.213 \\
PU4 & 0.693 & 0.531 & 0.567 & 0.856 & 0.577 & 0.169 \\
QS1 & 0.470 & 0.407 & 0.373 & 0.426 & 0.833 & 0.125 \\
QS2 & 0.573 & 0.536 & 0.433 & 0.539 & 0.901 & 0.182 \\
QS3 & 0.528 & 0.478 & 0.414 & 0.521 & 0.865 & 0.147 \\
QS4 & 0.622 & 0.453 & 0.453 & 0.548 & 0.912 & 0.162 \\
QS5 & 0.655 & 0.523 & 0.433 & 0.558 & 0.931 & 0.162 \\
QS6 & 0.630 & 0.515 & 0.429 & 0.558 & 0.917 & 0.232 \\
XS1 & 0.158 & 0.105 & 0.158 & 0.266 & 0.150 & 0.808 \\
XS2 & 0.123 & 0.079 & -0.035 & 0.146 & 0.190 & 0.856 \\
XS3 & 0.157 & 0.095 & -0.034 & 0.104 & 0.126 & 0.880 \\
XS4 & 0.179 & 0.104 & 0.019 & 0.144 & 0.131 & 0.722 \\
XS5 & 0.196 & 0.149 & 0.038 & 0.120 & 0.124 & 0.912 \\
XS6 & 0.259 & 0.215 & 0.187 & 0.237 & 0.199 & 0.899 \\
\hline & & & & & & \\
\hline
\end{tabular}


Table 5 Discriminant validity (HTMT)

\begin{tabular}{lllllll}
\hline & AT & BI & PEU & PU & SQ & XS \\
\hline AT & & & & & & \\
BI & 0.838 & & & & & \\
PEU & 0.648 & 0.585 & & & & \\
PU & 0.866 & 0.699 & 0.615 & & & \\
SQ & 0.709 & 0.585 & 0.532 & 0.635 & & \\
XS & 0.230 & 0.160 & 0.131 & 0.218 & 0.189 & \\
\hline
\end{tabular}

e-learning $(X S)$, with $(\beta=0.117, \mathrm{t}$-value $=0.813, \mathrm{p}>0.05)$, did not significantly affect PEU. Therefore, hypothesis 4 was not supported.

SQ $(\beta=0.417, \mathrm{t}-$ value $=4.822, \mathrm{p}<0.001)$ and PEU $(\beta=0.317, \mathrm{t}$-value $=4.056$, $\mathrm{p}<0.001)$ significantly affected PU. Therefore, hypothesis 1 and hypothesis 6 were supported. In term of effect size, referring to Cohen (2013), $\mathrm{f}^{2}$ for SQ (0.237) and PU (0. 140) were regarded as small effect size. On the other hand, XS $(\beta=0.120$, $\mathrm{t}$-value $=1.431, \mathrm{p}>0.05)$ did not significantly affect PU.

In respect of attitude toward using (AT), SQ $(\beta=0.270$, t-value $=3.447$, $\mathrm{p}<0.001)$, PEU $(\beta=0.141, \mathrm{t}$-value $=2.138, \quad \mathrm{p}<0.05)$ and $\mathrm{PU} \quad(\beta=0.535$, $\mathrm{t}$-value $=6.951, \mathrm{p}<0.001)$ significantly influenced AT. Hence, hypothesis 2 , hypothesis 7 and hypothesis 8 were supported. Effect sizes for SQ (0.134) and PEU (0.041) were considered small, while the effect size for PU (0.489) was considered large.

Concerning behavioural intention (BI), only one out of three relationships were found to have $\mathrm{t}$ values $>1.645$. AT significantly affected BI $(\beta=0.604$, $\mathrm{t}$-value $=5.299, \mathrm{p}<0.001)$. Therefore, hypothesis 10 was supported. However, SQ $(\beta=0.081, \mathrm{t}$-value $=1.062, \mathrm{p}>0.05)$ and PU $(\beta=-0.119, \mathrm{t}$-value $=1.033$, $\mathrm{p}>0.05)$ did not significantly affect BI. Therefore, Hypothesis 3 and Hypothesis 9 were rejected. According to Cohen (2013), $\mathrm{f}^{2}$ for AT (0.204) was considered as a large effect. Finally, Table 7 highlights summary of the results of hypothesis testing.

Table 6 Lateral collinearity assessment and hypothesis testing

\begin{tabular}{|c|c|c|c|c|c|c|c|c|}
\hline Hyps & Relationship & VIF & Std Error & Std Beta & t-value & $\mathrm{P}$ Value & $\mathrm{R}^{2}$ & $\mathrm{f}^{2}$ \\
\hline H1 & $\mathrm{SQ} \rightarrow \mathrm{PU}$ & 1.320 & 0.087 & 0.417 & 4.822 & 0.000 & 0.443 & 0.237 \\
\hline $\mathrm{H} 2$ & $\mathrm{SQ} \rightarrow \mathrm{AT}$ & 1.625 & 0.078 & 0.270 & 3.447 & 0.000 & 0.666 & 0.134 \\
\hline $\mathrm{H} 3$ & $\mathrm{SQ} \rightarrow \mathrm{BI}$ & 1.803 & 0.076 & 0.081 & 1.062 & 0.145 & 0.571 & 0.009 \\
\hline $\mathrm{H} 4$ & $\mathrm{XS} \rightarrow \mathrm{PEU}$ & 1.000 & 0.144 & 0.117 & 0.813 & 0.209 & 0.014 & 0.014 \\
\hline H5 & $\mathrm{XS} \rightarrow \mathrm{PU}$ & 1.039 & 0.084 & 0.120 & 1.431 & 0.077 & & 0.025 \\
\hline H6 & $\mathrm{PEU} \rightarrow \mathrm{PU}$ & 1.290 & 0.078 & 0.317 & 4.056 & 0.000 & & 0.140 \\
\hline $\mathrm{H} 7$ & $\mathrm{PEU} \rightarrow \mathrm{AT}$ & 1.470 & 0.066 & 0.141 & 2.138 & 0.017 & & 0.041 \\
\hline H8 & $\mathrm{PU} \rightarrow \mathrm{AT}$ & 1.750 & 0.077 & 0.535 & 6.951 & 0.000 & & 0.489 \\
\hline H9 & $\mathrm{PU} \rightarrow \mathrm{BI}$ & 2.532 & 0.115 & 0.119 & 1.033 & 0.151 & & 0.013 \\
\hline H10 & $\mathrm{AT} \rightarrow \mathrm{BI}$ & 2.873 & 0.114 & 0.604 & 5.299 & 0.000 & & 0.295 \\
\hline
\end{tabular}




\section{Discussion}

The present study mainly attempts to evaluate factors that contribute to university students' behavioural intention in using e-learning during the COVID-19 outbreak. This study is distinct from the previous studies since it investigated college students who would be secondary school teachers at a university in a developing country where the use of e-learning is not familiar to students. Hence, it is necessary to investigate this issue to advance understanding of what factors play a critical role in the use of e-learning among students. To explore this issue, we adopted the TAM model (Davis et al., 1989), with external factors of their prior e-learning experiences in high schools and quality of e-learning system being used at university. The hypotheses related to TAM scales and the external factors were examined. This study shows three important points of discussion.

First, students' prior e-learning experiences in high schools did not significantly affect PEU and PU of e-learning at university. This finding contradicts previous studies that showed prior experience gave a positive impact on users' PEU and PU (Lau \& Woods, 2008; Lee et al., 2013; Martin, 2012; Rezaei et al., 2008; Williams \& Williams, 2010). However, there are several existing studies that indicated that prior experience does not have a significant impact on users' acceptance of e-learning. For instance, Hrtoňová et al. (2015) claim that prior experience with e-learning does not play a significant role because digital technologies are becoming an ordinary part of education. Furthermore, they argued that their finding contradicts the literature because their study focuses specifically on prior experience with e-learning. In the present study, we also addressed a very specific experience, which is the e-learning experience when the students studied in high schools. Therefore, we argue that the insignificant effect of e-learning experience on PEU and PEU happens because we assessed a specific type of experience. Another possible reason that can explain this finding is that results of the quantitative analysis showed that students' average score on e-learning experience was very low, indicating they have insufficient experience of utilising e-learning when they studied in high schools. Low adoption of e-learning in secondary schools has been revealed by (Mailizar \& Fan, 2020). A number of students who did not have

Table 7 Results of hypothesis

\begin{tabular}{lllll}
\hline Hypothesis & Effects & Direction & Path Coefficient & Conclusion \\
\hline H1 & SQ $\rightarrow$ PU & Positive & 0.417 & Supported \\
H2 & SQ $\rightarrow$ AT & Positive & 0.270 & Supported \\
H3 & SQ $\rightarrow$ BI & Positive & 0.081 & Not supported \\
H4 & XS $\rightarrow$ PEU & Positive & 0.117 & Not supported \\
H5 & XS $\rightarrow$ PU & Positive & 0.120 & Not supported \\
H6 & PEU $\rightarrow$ PU & Positive & 0.317 & Supported \\
H7 & PEU $\rightarrow$ AT & Positive & 0.141 & Supported \\
H8 & PU $\rightarrow$ AT & Positive & 0.535 & Supported \\
H9 & PU $\rightarrow$ BI & Positive & 0.119 & Not supported \\
H10 & AT $\rightarrow$ BI & Positive & 0.604 & Supported \\
\hline
\end{tabular}


experience with e-learning in high school might have had extensive experience with using other digital technologies, which may lead them to not having difficulties with working in an online environment (Hrtoňová et al., 2015). In addition, this finding may be shaped by other factors, including students have been using e-learning during the pandemic without proper preparation. In the context of COVID 19, Sukendro et al. (2020) showed that perceived usefulness did not significantly affect students' attitude toward e-learning. This finding is also not in line with the mainstream literature regarding the acceptance of e-learning.

Second, e-learning quality played a significant impact on students' perceived usefulness (PU) and attitude toward using (AT) but insignificantly affected behavioural intention (BI) to utilise e-learning. This finding confirms prior studies that suggested system quality positively affected perceived usefulness (Fathema \& Sutton, 2013; Park et al., 2012) and attitude (Fathema \& Sutton, 2013). However, the finding of the present study challenges the previous studies revealing that system quality significantly influenced behavioural intention to adopt e-learning (Fathema \& Sutton, 2013; Park et al., 2012). This finding indicates that aspect related to technical quality of the system such as ease of access, capacity of system to meeting user' need, and flexibility of the system are all important aspect and contribute to perceived of usefulness of e-learning system during the university closured due to the COVID 19 pandemic where the users were not well prepared to use such system.

Third, regarding attitude toward using (AT) of learning management system, this current study suggests that system quality, perceived ease of use and perceived usefulness significantly affected attitude toward using e-learning. Furthermore, PU was the strongest predictor of AT. Previous studies have shown the urgency of PU for attitude toward using e-learning (Hamid et al., 2016; Hess et al., 2014; Mou et al., 2017). Accordingly, this finding agrees to our prediction that SQ, PEU and PU of e-learning significantly affected students' attitude toward using e-learning.

Fourth, in relation to students' BI, our findings pointed out that only attitude significantly influenced intention to use e-learning. Similarly, several prior research have found the criticality of attitude (AT) for behavioural intention (Hussein, 2017; Letchumanan \& Tarmizi, 2011; Sharma \& Chandel, 2013; Taat \& Francis, 2019). In contrast with mainstream literature, the present study suggested that system quality and perceived usefulness insignificantly influenced students' intention toward e-learning use. With regard to PU, previous studies have shown that perceived usefulness (PU) directly affected usage intention of e-learning (Al-Gahtani, 2016; Elkaseh et al., 2016; Hsia et al., 2014; Lee et al., 2014; Tarhini et al., 2014, 2016). In connection with QS, previous studies also reported that it significantly affected user's intention (Fathema \& Sutton, 2013; Fathema et al., 2015; Park et al., 2012; Rafique et al., 2020). Nevertheless, a few studies found the similar findings that PU was non-significant to the prediction of behavioural intention toward e-learning use (Lew et al., 2019). According to Lew et al. (2019), the insignificant effect of perceived usefulness toward behavioural intention indicates that resistance towards new technology may not be as crucial as it once was. For example, perceived usefulness was also a weak predictor for students' behavioural intention to use YouTube for procedural learning (Lee \& Lehto, 2013) and student behavioural intention to adopt mobile technology for student-teacher interactions (Sim \& Finger, 2012). The insignificant impact of perceived usefulness on students' intention 
to use e-learning may signify a shift in the thinking paradigm among users who are adept and savvy with digital technologies (Gan \& Balakrishnan, 2018). Furthermore, this study took place during the university closure in the COVID-19 pandemic. In this situation, there are limited options available to support remote learning, one of them is a learning management system. In such circumstance, when students did not have many options for remote learning, perceived usefulness, and system quality of e-learning might become less important factors for them in deciding to use the technology. For that reason, this study leaves this issue for future works that need to be explored.

\section{Concluding remarks}

This study proposes a model for understanding university students' intention to adopt e-learning while the spread of COVID-19 prevents the conventional learning. The technology acceptance model (TAM) was employed for analysis in which system quality and e-learning experience were included as external constructs. The proposed theoretical model effectively explains the behavioural intention $(\mathrm{R} 2=0.571)$ of university students to use the e-learning system during the COVID 19 pandemic. The findings suggested that system quality strongly affected students' perceived usefulness and attitude toward e-learning. On the other hand, prior e-learning experience did not significantly affect students' perceived ease of use and perceived usefulness of e-learning. Furthermore, students' behavioural intention to utilise e-learning during the outbreak was significantly influenced by attitude toward e-learning.

This study suggests that for students who are not familiar with e-learning at the university to be willing to continue using e-learning during the pandemic and beyond, system quality and their attitude toward e-learning are vital. Therefore, this study indicates that it is crucial to ensure that the university has a good quality of the e-learning system. Furthermore, the university also needs to maintain a positive student attitude toward e-learning as it is the most significant factor to predict student use of e-learning. This study showed that students attitude was significantly influenced by their perceived ease of use and perceived usefulness of e-learning. Based on those relationships, we conclude that to ensure the sustainable use of e-learning during the pandemic and beyond, the quality of the e-learning system is crucial. Therefore, universities must maintain and improve the quality of the system.

Finally, it is worth acknowledging several limitations of this study and addressing them ahead. First, the participants of this current study were only from one university in Indonesia. It might shape the generalizability of the findings. Also, in terms of gender, the participants of this study dominated by female students $(88.7 \%)$ while male students only $11.3 \%$. This imbalanced gender representation might slightly provide a biased result. Second, the present study only included two external factors, namely prior e-learning experience and system quality. At the same time, other external factors of behavioural intention to use e-learning during the pandemic may also exist. As a result, any future studies should consider other external variables of e-learning adoption. Last, as the present study showed that system quality and perceived usefulness did not significantly affect university students' behavioural intention to adopt e-learning during the outbreak of COVID-19; thus, it needs a further study aiming to explore this issue. 


\section{Appendix}

Table 8 Items of the survey instrument in English after assessment of the measurement model

Prior e-learning experience in high schools (XS)

$\mathrm{XS} 1$

XS 2

XS 3

XS 4

XS 5

XS 6

E-learning system quality (SQ)

SQ1

SQ2

SQ3

SQ4

SQ5

SQ6

Perceived Usefulness (PU)

PU1

PU2

PU3

PU4

Perceived Ease of Use (PEU)

PEU2

PEU3

PEU4

Attitude (AT)

AT1

AT2

AT3

AT4

Behavioural Intention

BI1

BI2

$\mathrm{BI} 3$
My high school had a learning management system

I used e-learning when I was in a high school

I submitted assignment via e-learning when I was in a high school

When I was in high school, I used e-learning for searching for learning resources My high school teachers provided an assignment on the e-learning system My high school teachers communicated with students via an e-learning system

The layout of the information at my university's e-learning website is easy to follow

My university's e-learning course website allows me to find information easily

It is easy for me to complete a transaction through my university's e-learning website

I do not encounter long delays when searching for information on my university's e-learning website

My university's e-learning course website is visually appealing

I feel secure in providing sensitive information through my university's e-learning website

The use of e-learning during university closure due to the COVID 19 pandemic helps me to access learning resources

Using e-learning will improve learning performance in distance learning during the COVID 19 pandemic

The use of e-learning will increase my productivity in distance learning during the COVID 19 pandemic

The use of e-learning is beneficial for my learning activities during the COVID 19 pandemic

Learning to use e-learning system in distance learning during the COVID 19 pandemic is easy

It is easy to navigate my university's e-learning system in distance learning during the COVID 19 pandemic

The use of an e-learning system during the COVID 19 pandemic is flexible

I like the use of the e-learning system during the COVID 19 pandemic

The use of an e-learning system during the COVID 19 pandemic is a good idea

The use of an e-learning system during the COVID 19 pandemic is an interesting idea

I think the use of e-learning system is a trend during the COVID 19 pandemic

I want all courses are offered via an e-learning system during COVID 19 and beyond

I will use e-learning if it is available in the post-COVID 19 pandemics

I will recommend using an e-learning system in the future 
Acknowledgements We would like to thank all individuals participated in this study and also Realistic Mathematics Education Research Centre, Syiah Kuala University for the substantial contribution to this study.

\section{References}

Abbasi, M. S., Chandio, F. H., Soomro, A. F., \& Shah, F. (2011). Social influence, voluntariness, experience and the internet acceptance: An extension of technology acceptance model within a southAsian country context. Journal of Enterprise Information Management, 24(1), 30-55. https://doi. org/10.1108/17410391111097410.

Abdullah, F., \& Ward, R. (2016). Developing a General Extended Technology Acceptance Model for E-Learning (GETAMEL) by analysing commonly used external factors. Computers in Human Behavior, 56, 238-256. https://doi.org/10.1016/j.chb.2015.11.036.

Abdullah, F., Ward, R., \& Ahmed, E. (2016). Investigating the influence of the most commonly used external variables of TAM on students' Perceived Ease of Use (PEOU) and Perceived Usefulness (PU) of e-portfolios. Computers in human behavior, 63, 75-90.

Al-Adwan, A., Al-Adwan, A., \& Smedley, J. (2013). Exploring students acceptance of e-learning using Technology Acceptance Model in Jordanian universities. International Journal of Education and Development using ICT, 9(2), 4-18. https://www.learntechlib.org/p/130283/.

Al-alak, B. A., \& Alnawas, I. A. (2011). Measuring the acceptance and adoption of e-learning by academic staff. Knowledge Management \& E-Learning: An International Journal, 3(2), 201-221.

Al-Gahtani, S. S. (2016). Empirical investigation of e-learning acceptance and assimilation: A structural equation model. Applied Computing and Informatics, 12(1), 27-50. https://doi.org/10.1016/j.aci. 2014.09.001.

Almaiah, M. A., Al-Khasawneh, A., \& Althunibat, A. (2020). Exploring the critical challenges and factors influencing the E-learning system usage during COVID-19 pandemic. Education and Information Technologies, 25, 5261-5280.

Armenteros, M., Liaw, S.-S., Fernández, M., Díaz, R. F., \& Sánchez, R. A. (2013). Surveying FIFA instructors' behavioral intention toward the multimedia teaching materials. Computers \& Education, 61, 91-104. https://doi.org/10.1016/j.compedu.2012.09.010.

Binyamin, S. S., Rutter, M., \& Smith, S. (2019). Extending the technology acceptance model to understand students' use of learning management systems in saudi higher education. International Journal of Emerging Technologies in Learning (iJET), 14(03), 4-21. https://doi.org/10. 3991/ijet.v14i03.9732.

Chang, C.-T., Hajiyev, J., \& Su, C.-R. (2017). Examining the students' behavioral intention to use e-learning in Azerbaijan? The general extended technology acceptance model for e-learning approach. Computers \& Education, 111, 128-143. https://doi.org/10.1016/j.compedu.2017.04. 010 .

Cheung, R., \& Vogel, D. (2013). Predicting user acceptance of collaborative technologies: An extension of the technology acceptance model for e-learning. Computers \& Education, 63, 160-175. https:// doi.org/10.1016/j.compedu.2012.12.003.

Chu, T.-H., \& Chen, Y.-Y. (2016). With good we become good: Understanding e-learning adoption by theory of planned behavior and group influences. Computers \& Education, 92, 37-52. https://doi. org/10.1016/j.compedu.2015.09.013.

Cigdem, H., \& Topcu, A. (2015). Predictors of instructors' behavioral intention to use learning management system: A Turkish vocational college example. Computers in Human Behavior, 52, 22-28. https://doi.org/10.1016/j.chb.2015.05.049.

Cohen, J. (2013). Statistical Power Analysis for the Behavioral Sciences. Academic Press.

Cruz-Cárdenas, J., Zabelina, E., Deyneka, O., Guadalupe-Lanas, J., \& Velín-Fárez, M. (2019). Role of demographic factors, attitudes toward technology, and cultural values in the prediction of technology-based consumer behaviors: A study in developing and emerging countries. Technological Forecasting and Social Change, 149, 119768.

Dahlstrom, E., Brooks, D. C., \& Bichsel, J. (2014). The Current Ecosystem of Learning Management Systems in Higher Education: Student, Faculty, and IT Perspectives. Educause. https://www.educa use.edu/ecar. 
Davis. (1986) A technology acceptance model for empirically testing new ensd-user information systems: Theory and results Massachusetts Institute of Technology.

Davis, F. D. (1989). Perceived usefulness, perceived ease of use, and user acceptance of information technology. MIS quarterly, 13(3), 319-340. https://doi.org/10.2307/249008.

Davis, F. D., Bagozzi, R. P., \& Warshaw, P. R. (1989). User acceptance of computer technology: A comparison of two theoretical models. Management Science, 35(8), 982-1003. https://doi.org/10.1287/ mnsc.35.8.982.

De Smet, C., Bourgonjon, J., De Wever, B., Schellens, T., \& Valcke, M. (2012). Researching instructional use and the technology acceptation of learning management systems by secondary school teachers. Computers \& Education, 58(2), 688-696.

Elkaseh, A. M., Wong, K. W., \& Fung, C. C. (2016). Perceived ease of use and perceived usefulness of social media for e-learning in Libyan higher education: A structural equation modeling analysis. International Journal of Information and Education Technology, 6(3), 192. https://doi.org/10.7763/ ijiet.2016.v6.683.

Fathema, N., \& Sutton, K. L. (2013). Factors influencing faculty members' Learning Management Systems adoption behavior: An analysis using the Technology Acceptance Model. International Journal of Trends in Economics Management \& Technology (IJTEMT), 2(6), 20-28. https://www.ijtemt. org

Fathema, N., Shannon, D., \& Ross, M. (2015). Expanding the Technology Acceptance Model (TAM) to examine faculty use of Learning Management Systems (LMSs) in higher education institutions. Journal of Online Learning \& Teaching, 11(2), 1-23.

Fokides, E. (2017). Greek pre-service teachers' intentions to use computers as in-service teachers. Contemporary Educational Technology, 8(1), 56-75. https://doi.org/10.30935/cedtech/6187.

Fraenkel, Wallen, N. E., \& Hyun, H. H. (2011). How to design and evaluate research in education. McGraw-Hill Humanities/Social Sciences/Languages.

Gan, C. L., \& Balakrishnan, V. (2018). Mobile technology in the classroom: What drives student-lecturer interactions? International Journal of Human-Computer Interaction, 34(7), 666-679.

Hair, J. F., Hult, G. T. M., Ringle, C., \& Sarstedt, M. (2016). A primer on partial least squares structural equation modeling (PLS-SEM). Sage Publications.

Hair, J. F., Hult, G. T. M., Ringle, C., \& Sarstedt, M. (2017). A primer on partial least squares structural equation modeling (PLS-SEM). Sage Publications.

Hamid, A. A., Razak, F. Z. A., Bakar, A. A., \& Abdullah, W. S. W. (2016). The effects of perceived usefulness and perceived ease of use on continuance intention to use e-government. Procedia Economics and Finance, 35(2016), 644-649. https://doi.org/10.1016/s2212-5671(16)00079-4.

Henseler, J. (2010). On the convergence of the partial least squares path modeling algorithm. Computational Statistics, 25(1), 107-120. https://doi.org/10.1007/s00180-009-0164-x.

Henseler, J., Ringle, C. M., \& Sarstedt, M. (2015). A new criterion for assessing discriminant validity in variance-based structural equation modeling. Journal of the Academy of Marketing Science, 43(1), 115-135. https://doi.org/10.1007/s11747-014-0403-8.

Hess, T. J., McNab, A. L., \& Basoglu, K. A. (2014). Reliability generalization of perceived ease of use, perceived usefulness, and behavioral intentions. MIS Quarterly, 38(1), 1-28. https://doi.org/10. 25300/misq/2014/38.1.01.

Ho, N. T. T., Sivapalan, S., Pham, H. H., Nguyen, L. T. M., Van Pham, A. T., \& Dinh, H. V. (2020). Students' adoption of e-learning in emergency situation: the case of a Vietnamese university during COVID-19. Interactive Technology and Smart Education, 17(4), 1-24. https://doi.org/10.1108/ ITSE-08-2020-0164.

Hrtoňová, N., Kohout, J., Rohlíková, L., \& Zounek, J. (2015). Factors influencing acceptance of e-learning by teachers in the Czech Republic. Computers in Human Behavior, 51, 873-879.

Hsia, J.-W., Chang, C.-C., \& Tseng, A.-H. (2014). Effects of individuals' locus of control and computer self-efficacy on their e-learning acceptance in high-tech companies. Behaviour \& Information Technology, 33(1), 51-64. https://doi.org/10.1080/0144929x.2012.702284.

Hussein, Z. (2017). Leading to intention: The role of attitude in relation to technology acceptance model in e-learning. Procedia Computer Science, 105, 159-164.

Joo, Y. J., Park, S., \& Lim, E. (2018). Factors influencing preservice teachers' intention to use technology: TPACK, teacher self-efficacy, and technology acceptance model. Journal of Educational Technology \& Society, 21(3), 48-59.

Kaplan, K. J. (1972). On the ambivalence-indifference problem in attitude theory and measurement: A suggested modification of the semantic differential technique. Psychological Bulletin, 77(5), 361. 
Kawano, S., \& Kakehashi, M. (2015). Substantial impact of school closure on the transmission dynamics during the pandemic flu H1N1-2009 in Oita, Japan. PloS one, 10(12), 1-15. https://doi.org/10.1371/ journal.pone.0144839.

Lau, S.-H., \& Woods, P. C. (2008). An empirical study of learning object acceptance in multimedia learning environment. Communications of the IBIMA, 5(1), 1-6.

Lee, D. Y., \& Lehto, M. R. (2013). User acceptance of YouTube for procedural learning: An extension of the technology acceptance model. Computers \& Education, 61, 193-208.

Lee, Y.-H., Hsiao, C., \& Purnomo, S. H. (2014). An empirical examination of individual and system characteristics on enhancing e-learning acceptance. Australasian Journal of Educational Technology, 30(5), 562-579. https://doi.org/10.14742/ajet.381.

Lee, Y.-H., Hsieh, Y.-C., \& Chen, Y.-H. (2013). An investigation of employees' use of e-learning systems: Applying the technology acceptance model. Behaviour \& Information Technology, 32(2), 173-189. https://doi.org/10.1080/0144929x.2011.577190.

Lee, Y.-H., Hsieh, Y.-C., \& Ma, C.-Y. (2011). A model of organizational employees'e-learning systems acceptance. Knowledge-based systems, 24(3), 355-366. https://doi.org/10.1016/j.knosys.2010.09. 005 .

Letchumanan, M., \& Tarmizi, R. (2011). Assessing the intention to use e-book among engineering undergraduates in Universiti Putra Malaysia. Malaysia. Library Hi Tech, 29(3), 512-528. https://doi.org/ 10.1108/07378831111174459.

Lew, S.-L., Lau, S.-H., \& Leow, M.-C. (2019). Usability factors predicting continuance of intention to use cloud e-learning application. Heliyon, 5(6), e01788.

Lin, K.-M., Chen, N.-S., \& Fang, K. (2010). Understanding e-learning continuance intention: A negative critical incidents perspective. Behaviour \& Information Technology, 30(1), 77-89. https://doi.org/ 10.1080/01449291003752948.

Liu, I.-F., Chen, M. C., Sun, Y. S., Wible, D., \& Kuo, C.-H. (2010). Extending the TAM model to explore the factors that affect Intention to Use an Online Learning Community. Computers \& Education, 54(2), 600-610. https://doi.org/10.1016/j.compedu.2009.09.009.

Lynn, M. R. (1986). Determination and quantification of content validity. Nursing Research, 35(6), 382-385.

Mailizar, M., \& Fan, L. (2020). Examining Indonesian secondary school mathematics teachers' instructional practice in the integration of technology. Universal Journal of Educational Research, 8(10), 4692-4699.

Martin, R. G. (2012). Factors affecting the usefulness of social networking inE-learning at German University of Technology in Oman. International Journal of e-Education, e-Business, e-Management and e-Learning, 2(6), 498. https://doi.org/10.7763/ijeeee.2012.v2.171.

Martinho, D. S., Santos, E. M., Miguel, M. I., \& Cordeiro, D. S. (2018). Factors that influence the adoption of postgraduate online courses. International Journal of Emerging Technologies in Learning (iJET), 13(12), 123-141. https://doi.org/10.3991/ijet.v13i12.8864.

McGill, T., Klobas, J., \& Renzi, S. (2011). LMS use and instructor performance: The role of task-technology fit. International Journal on E-Learning, 10(1), 43-62.

Mou, J., Shin, D.-H., \& Cohen, J. (2017). Understanding trust and perceived usefulness in the consumer acceptance of an e-service: A longitudinal investigation. Behaviour \& Information Technology, 36(2), 125-139. https://doi.org/10.1080/0144929x.2016.1203024.

Park, S. Y., Nam, M. W., \& Cha, S. B. (2012). University students' behavioral intention to use mobile learning: Evaluating the technology acceptance model. British Journal of Educational Technology, 43(4), 592-605. https://doi.org/10.1111/j.1467-8535.2011.01229.x.

Pham, L., Limbu, Y. B., Bui, T. K., Nguyen, H. T., \& Pham, H. T. (2019). Does e-learning service quality influence e-learning student satisfaction and loyalty? Evidence from Vietnam. International Journal of Educational Technology in Higher Education, 16(1), 1-26.

Premchaiswadi, W., Porouhan, P., \& Premchaiswadi, N. (2012). An empirical study of the key success factors to adopt e-learning in Thailand. International conference on information society (i-Society 2012).

Purnomo, S. H., \& Lee, Y.-H. (2013). E-learning adoption in the banking workplace in Indonesia: An empirical study. Information Development, 29(2), 138-153. https://doi.org/10.1177/0266666912 448258.

Rafique, H., Almagrabi, A. O., Shamim, A., Anwar, F., \& Bashir, A. K. (2020). Investigating the acceptance of mobile library applications with an extended technology acceptance model (TAM). Computers \& Education, 145, 103732. https://doi.org/10.1016/j.compedu.2019.103732. 
Rezaei, M., Mohammadi, H. M., Asadi, A., \& Kalantary, K. (2008). Predicting e-learning application in agricultural higher education using technology acceptance model. Turkish Online Journal of Distance Education, 9(1), 85-95.

Ritter, N. L. (2017). Technology acceptance model of online learning management systems in higher education: A meta-analytic structural equation model. International Journal of Learning Management Systems, 5(1), 1-15. https://doi.org/10.18576/ijlms/050101.

Scherer, R., Siddiq, F., \& Tondeur, J. (2019). The technology acceptance model (TAM): A meta-analytic structural equation modeling approach to explaining teachers' adoption of digital technology in education. Computers \& Education, 128, 13-35. https://doi.org/10.1016/j.compedu.2018.09.009.

Sharma, S., \& Chandel, J. (2013). Technology acceptance model for the use of learning through websites among students In Oman. International Arab Journal of E-Technology, 3(1), 44-49.

Sim, C., \& Finger, G. (2012).It's time to technological pedagogical reason ACEC2012: ITs Time Conference, Perth, Australia.

Siron, Y., Wibowo, A., \& Narmaditya, B. S. (2020). Factors affecting the adoption of e-learning in Indonesia: Lesson from Covid-19. JOTSE: Journal of Technology and Science Education, 10(2), 282-295.

Sukendro, S., Habibi, A., Khaeruddin, K., Indrayana, B., Syahruddin, S., Makadada, F. A., \& Hakim, H. (2020). Using an extended Technology Acceptance Model to understand students' use of e-learning during Covid-19: Indonesian sport science education context. Heliyon, 6(11), e05410.

Taat, M. S., \& Francis, A. (2019). Factors influencing the students' acceptance of e-learning at teacher education institute: An exploratory study in Malaysia. The International Journal of Higher Education, 9, 133. https://doi.org/10.5430/ijhe.v9n1p133.

Tarhini, A., Elyas, T., Akour, M. A., \& Al-Salti, Z. (2016). Technology, demographic characteristics and e-learning acceptance: A conceptual model based on extended technology acceptance model. Higher Education Studies, 6(3), 72-89. https://doi.org/10.5539/hes.v6n3p72.

Tarhini, A., Hassouna, M., Abbasi, M. S., \& Orozco, J. (2015). Towards the acceptance of RSS to support learning: An empirical study to validate the technology acceptance model in Lebanon. Electronic Journal of e-Learning, 13(1), 30-41.

Tarhini, A., Hone, K., \& Liu, X. (2014). The effects of individual differences on e-learning users' behaviour in developing countries: A structural equation model. Computers in Human Behavior, 41, 153163. https://doi.org/10.1016/j.chb.2014.09.020.

Teo, T. (2010). A path analysis of pre-service teachers' attitudes to computer use: Applying and extending the technology acceptance model in an educational context. Interactive Learning Environments, 18(1), 65-79. https://doi.org/10.1080/10494820802231327.

Teo, T. (2012). Examining the intention to use technology among pre-service teachers: An integration of the technology acceptance model and theory of planned behavior. Interactive Learning Environments, 20(1), 3-18.

Teo, T., Milutinović, V., Zhou, M., \& Banković, D. (2017). Traditional vs. innovative uses of computers among mathematics pre-service teachers in Serbia. Interactive Learning Environments, 25(7), 811-827.

Tosuntaş, ŞB., Karadağ, E., \& Orhan, S. (2015). The factors affecting acceptance and use of interactive whiteboard within the scope of FATIH project: A structural equation model based on the Unified Theory of acceptance and use of technology. Computers \& Education, 81, 169-178. https://doi.org/ 10.1016/j.compedu.2014.10.009.

Venkatesh, V., \& Bala, H. (2008). Technology acceptance model 3 and a research agenda on interventions. Decision sciences, 39(2), 273-315.

Vladova, G., Ullrich, A., Bender, B., \& Gronau, N. (2021). Students' Acceptance of Technology-Mediated Teaching-How It Was Influenced During the COVID-19 Pandemic in 2020: A Study From Germany. Frontiers in Psychology, 12(1), 1-15. https://doi.org/10.3389/fpsyg.2021.636086.

Waheed, M., \& Jam, F. A. (2010). Teacher's intention to accept online education: Extended TAM model. Interdisciplinary Journal of Contemporary Research in Business, 2(5), 330-344.

Wheeler, C. C., Erhart, L. M., \& Jehn, M. L. (2010). Effect of school closure on the incidence of influenza among school-age children in Arizona. Public Health Reports, 125(6), 851-859. https://doi. org/10.1177/003335491012500612.

Williams, M., \& Williams, J. (2010). Evaluating a model of business school students' acceptance of webbased course management systems. The International Journal of Management Education, 8(3), 59-70. https://doi.org/10.3794/ijme.83.264. 
Wong, G. K. (2015). Understanding technology acceptance in pre-service teachers of primary mathematics in Hong Kong. Australasian Journal of Educational Technology, 31(6). https://doi.org/10.14742/ ajet. 1890 .

Zogheib, B., Rabaa'i, A., Zogheib, S., \& Elsaheli, A. (2015). University student perceptions of technology use in mathematics learning. Journal of Information Technology Education, 14, 417-438.

Publisher's note Springer Nature remains neutral with regard to jurisdictional claims in published maps and institutional affiliations.

\section{Authors and Affiliations}

\section{Mailizar Mailizar $^{1}$ (D) Damon Burg ${ }^{2}$ (D) Suci Maulina ${ }^{3}$}

Damon Burg

damonburg@gmail.com

Suci Maulina

sucimaulina@gmail.com

1 Mathematics Education Department, Universitas Syiah Kuala, 23111 Banda Aceh, Indonesia

2 School of Education, Yong In University, Yongin, South Korea

3 Realistic Mathematics Education Research Centre, Universitas Syiah Kuala, 23111 Banda Aceh, Indonesia 